\title{
An analysis of adult non-neoplastic nephrectomies at a tertiary care centre in Mumbai
}

\author{
Fernandes $\mathbf{G}^{1}$ and Phadnis $\mathbf{P}^{2}$ \\ ${ }^{1}$ Dr. Gwendolyn Fernandes, Associate Professor and In-charge Uropathology service, ${ }^{2}$ Dr. Priyanka Phadnis, Fellow in \\ Uropathology, all authors are affiliated with Department of Pathology, Seth G. S. Medical College \& K.E.M Hospital, \\ Parel, Mumbai, Maharashtra, India.
}

Address for Correspondence: Dr. Gwendolyn Fernandes, C-802, Swayam, Poonam Gardens, Mira Road, Thane, Maharashtra, India, Email: drgwenfern@yahoo.co.in; drgwenfern@gmail.com

\begin{abstract}
Introduction: Nephrectomies are an integral part of urological practice and a wide range of ren al diseas es are seen on histopathological examination of non-n eoplastic nephrectomy specimens. Objective: The objective of this study was to assess the incidence, clinical presentation and the histological spectrum of various non-neoplastic renal diseases detected in nephrectomy specimens at our institute and to compare our observations with the conventional patterns seen. Material and Methods: This is a retrospective 6 year study of adult non-neoplastic nephrectomies (ANNN) conduct ed in a tertiary care centre in Mumbai and includes 359 cases from January 2009 to December 2015. The paraffin blocks and slides were retrieved from our archives and analysed along with clinical features, radiological findings. Results: 359 ANNN specimens received over a 6 year period were studied. Most of the patients were in the sixth decade with a slight female preponderance. Flank pain was the commonest presenting symptom seen in $79.94 \%$ of cas es. The most frequent surgical indication for ANNN was obstructive uropathy (47.08\%) which includes calculus disease and PUJ obstruction followed by non-functioning kidney (42.06\%). On histopathological examination, the most common gross pathology was acal culus hydronephrosis $(40.67 \%)$ and the most frequent histopathological diagnosis was chronic pyelon ephritis seen in $79.38 \%$ cases. Calculus obstructive uropathy amounted to $39.27 \%$ cases and acalculus obstructive urop athy amounted to $25.07 \%$ cases of chronic pyelonephritis. Conclusion: The most frequent surgical indication was obstructive uropathy and the most common histopathological diagnosis was chronic pyelonephritis. Calculus and acalculus obstructive uropathy amounted to almost $65 \%$ of the cases of chronic pyeloneph ritis.
\end{abstract}

Keywords: Non-neoplastic nephrectomy, nephrectomy, non-functioning kidney, chronic pyelonephritis, obstructive uropathy.

\section{Introduction}

Nephrectomies are a routine part of urological practice and a wide range of renal diseases are seen on histopathological examination. The commonest indication for a nephrectomy is a non-functional kidney or an irreversibly damaged kidney. Other common indications for nephrectomies include chronic in fection, obstruction, calculus disease and severe traum atic injury [1]. Today, with an increasing number of renal transplants, nephrectomies are also performed for renal allograft failure and a good histopathological

Manu script received: $7^{\text {th }}$ February 2017

Reviewed: $16^{\text {th }}$ February 2017

AuthorCorrected: $22^{\text {nd }}$ February 2017

Accepted forPublication: $28^{\text {th }}$ February 2017 examination is warranted. The number of nephrectomies has been gradually increasing in developing countries because of extensive use of imaging services and better access to health care facilities [2] and we have noticed a steady increase at our institute too.

The objective of this study was to assess the incidence, clinical presentation and the histological spectrum of various non-neoplastic renal diseas es detected in simple nephrectomy specimens. The study also aims to compare our observations with the conventional patterns seen. 


\section{Material and Methods}

This is a retrospective 6 year study of adult nonneoplastic nephrectomies (ANNN) conducted in a tertiary care centre in Mumbai. This study includes 359 cases from January 2009 to December 2015. The paraffin blocks and slides of these cas es were retrieved from our archives and analysed along with clinical features, radiological finding and histopathological examination which included gross and microscopy.

All the nephrectomies included in this study were received in $10 \%$ buffered form alin and were grossed according to standard grossing protocol. The kidneys were bisected, the cortex, medulla and pelvicalyceal system were examined in detail. Renal hilar structures which include renal artery, renal vein and ureter were also examined. Six to eight tissue sections including cortex and medulla and two sections including the hilar structures were taken and examined on light microscopy. Special stains like Gomori Methenamine silver stain, Periodic Acid Schiff, Masson Trichome and Ziehl Neelsen stain were used when ever required.

\section{Results}

The present study included a total of 359 ANNN specimens which were received during the 6 year study period from January 2009 - December 2015. $75(20.89 \%)$ of the patients in this study were in the age group 51- 60 years and 72 $(20.06 \%)$ patients who were in the age group of 21 - 30 years. [Table 1]. Gender-wise, $184(51.25 \%)$ were mal es and $175(48.75 \%)$ were femal es, with a male to female ratio of 1.05:1 [Table2].

Table-1: Age-wise distribution of the 359 Nephrectomi es.

\begin{tabular}{|c|c|c|}
\hline Age & $\mathbf{N = 3 5 9}$ & Percentage \\
\hline $11-20$ & 43 & 11.98 \\
\hline $21-30$ & 72 & 20.06 \\
\hline $31-40$ & 70 & 19.50 \\
\hline $41-50$ & 58 & $\mathbf{2 0 . 8 9}$ \\
\hline $\mathbf{5 1 - 6 0}$ & $\mathbf{7 5}$ & 9.75 \\
\hline $61-70$ & 35 & 1.67 \\
\hline $71-80$ & 6 & \\
\hline
\end{tabular}

Table-2: Gender-wise distribution of the 359 Nephrectomies

\begin{tabular}{|c|c|c|}
\hline Gender & $\mathbf{N}=\mathbf{3 5 9}$ & Percentage \\
\hline Male & 184 & 51.25 \\
\hline Female & 175 & 48.75 \\
\hline
\end{tabular}

As regards the clinical features, flank pain was the most common presenting symptom seen in $79.94 \%$ of cases $(287$ out of 359 cas es).

Flank pain was frequently associated with fever (42 out of 287 cases with fl ank pain) and urinary tract symptoms (21 out of 287 cas es with flank pain) such as burning micturition and increased frequency of micturition.

One patient presented with only fever and a non-functioning kidney was found on imaging studies. 7 out of 359 cases (1.94\%) were prospective transplant recipient with pyelonephritis in the native kidneys for which the kidneys were removed. 5 out 359 cases $(1.39 \%)$ were renal allografts that presented with complications such as renal vein thrombosis.

34 out of 359 cases $(9.47 \%$ ) were previously diagnosed cases with genitourinary tuberculosis (3 out of 359 cases, $0.84 \%$ ), pelviureteric (PUJ) obstruction (5 out of 359 cases, 1.39\%) [Table 3]. 
Table-3: Clinical presentation of the 359 Nephrectomies.

\begin{tabular}{|l|c|c|}
\hline Clinical Presentation & N = 359 & Percentage \\
\hline Flank pain & 287 & 79.94 \\
- Associated with fever & 42 & \\
- Associated with urinary tract symptoms & 21 & 0.28 \\
\hline Persistent fever & 1 & 1.95 \\
\hline Palpable flank mass & 7 & 1.39 \\
\hline Hematuria & 5 & 1.12 \\
\hline Severe nausea \& vomiting & 4 & 1.95 \\
\hline Prospective transplant recipient with pyelonephritis in native kidney & 7 & 1.39 \\
\hline Complications of renal allografts requiring nephrectomies & 5 & 2.51 \\
\hline Trauma & 9 & 9.47 \\
\hline Previously diagnosed cases with : & 34 & 0.84 \\
- Genito-urinary tuberculosis & 3 & 1.39 \\
- Pelvi-ureteral junction obstruction & 5 & 0.56 \\
- Pyonephrosis & 2 & 0.56 \\
- Renal calculus disease & 2 & 2.23 \\
- Calculus disease with prior surgery & 8 & 0.28 \\
- Neurogenic bladder & 1 & 0.28 \\
- Autotransplant of kidney & 1 & 0.28 \\
- Previous surgery for vesico-ureteral reflux & 1 & 0.28 \\
\hline Miscellaneous* & 1 & 2.23 \\
\hline
\end{tabular}

\section{* Miscellaneous}

1. Total abdominal hysterectomy and bilaterals-oophorectomy done for carcinoma cervix with left ureteric injury and left ureteric implant.

2. Surgery for pelvic mass 3 years ago for endom etriosis.

Table-4: Surgical indications of the 359 Nephrectomies.

\begin{tabular}{|l|c|c|}
\hline Surgical Indication for Nephrectomy & N=359 & Percentage \\
\hline $\begin{array}{l}\text { Obstructive uropathy (calculus disease and pelvi-ureteral junction } \\
\text { obstruction) }\end{array}$ & 169 & 47.08 \\
\hline $\begin{array}{l}\text { Non functioning kidney/ Chronic kidney disease } \\
\text { - Poorly functioning kidney with pus or hematoma }\end{array}$ & 151 & 42.06 \\
- Double moiety & 8 & \\
\hline Trauma & 9 & 3.90 \\
\hline Pyonephrosis & 14 & 0.28 \\
\hline Xanthogranulomatous pyelonephritis & 1 & 0.28 \\
\hline Emphysematous pyelonephritis & 1 & 1.95 \\
\hline Cystic disease & 7 & 0.84 \\
\hline Autosomal polycystic kidney disease & 3 & 1.39 \\
\hline Renal mass lesion ( non neoplastic ) & 5 & 0.28 \\
\hline Horseshoe kidney associat ed with & 1 & 1.11 \\
\hline Non functioning kidney with hydronephrosis & 4 & 1 \\
\hline Tuberculosis & 1 & \\
\hline Polycystic disease & 1 & 0.28 \\
\hline Nephal artery stenosis & 2 & 1 \\
\hline
\end{tabular}


Table-5: Gross finding of the 359 Nephrectomies.

\begin{tabular}{|l|c|c|}
\hline Gross Finding & N = 359 & Percentage \\
\hline Acalculus hydronephrosis & 146 & 40.67 \\
\hline Calculus disease with associated hydronephrosis & 119 & 33.15 \\
\hline Pyonephrosis & 4 & 1.11 \\
\hline Small contracted kidney/ atrophic kidney & 63 & 17.55 \\
\hline Polycystic kidney disease & 5 & 1.39 \\
\hline Calcified kidney & 2 & 0.56 \\
\hline Trauma- related changes & 8 & 2.23 \\
\hline Renal replacement lipomatosis & 4 & 1.11 \\
\hline Horseshoe kidney associat ed with & 3 & 0.84 \\
- Acalculus hydroneph rosis & 2 & 0.56 \\
$\bullet$ Caseous necrosis & 1 & 0.28 \\
\hline Graft nephrectomies & 5 & 1.39 \\
$\bullet$ Infarction subsequent to renal vein \& renal artery thrombosis & 4 & 1.11 \\
\hline
\end{tabular}

The most common surgical indication for nephrectomy in this study was obstructive uropathy seen in $47.08 \%$ (169 out of 359 cases) which includes calculus disease and PUJ obstruction, followed by non-functioning kidney seen in $42.06 \%$ (151 out of 359 cases). Other indications include pyonephrosis (14 out of 359 cases, 3.90\%), emphysematous pyelonephritis (7 out of 359 cases, 1.95\%). There were 5 cases with autosomal dominant polycystic kidney disease (ADPKD) and 3 cases of horseshoe kidney were encount ered which presented complications like tuberculosis, chronic pyelonephritis with hydronephrosis and associated polycystic kidney disease [Table 4].

On gross examination of the 359 cases, we observed that acalculus hydron ephrosis (146 out of 359 cases, $40.67 \%$ ) was the most common gross pathology followed by calculus disease with hydronephrosis (119 out of 359 cases, $33.15 \%$ ). Other gross pathologies include small contracted kidney (63 out of 359 cases, $17.55 \%$ ), pyonephrosis (4 out of 359 cases, $1.11 \%$ ), trauma related changes ( 8 out of 359 cas es, $2.23 \%$ ), renal replacement lipomatosis (4 out of 359 cas es, $1.11 \%$ ) and polycystic kidney disease (5 out of 359 cas es, $1.39 \%$ ). 5 cases $(1.39 \%)$ were renal allograft transplant and showed gross pathologies like infarction subsequent to renal vein thrombosis (4 out of 5) and acute pyelon ephritis with abscess (1 out of 5) [Table 5].

The histopathological examination of our 359 nephrectomies showed chronic pyelonephritis to be the commonest histopathological diagnosis in seen $79.38 \%$ (285 out of 359 cases). This figures include pure chronic pyelonephritis and acute on chronic pyelonephritis. Calculus obstructive uropathy was the most common underlying cause of chronic pyelonephritis (141 out of 359 cases, 39.27\%), followed by acalculus obstructive uropathy (90 out of 359 cases, $25.07 \%$ ).

Other causes of chronic pyelonephritis include granulomatous pyelonephritis (27 out of 359 cases, 7.52\%) which includes necrotising granulomatous pyelonephritis(23 out of 359 cases, 6.41\%) and non-necrotising granulomatous pyelonephritis (4 out of 359 cases, 1.11\%), xanthogranulomatous pyelonephritis (14 out of 359 cases, $3.90 \%$ ).

Other pathological diagnosis include progression to end stage disease or advanced renal disease (37 out of 359 cases, $10.31 \%$ ), graft neph rectomies (5 out of 359 cases, 1.39\%), ADPKD (5 out of 359 cases, 1.39\%), horseshoe kidney ( 3 out of 359 cas es, $0.84 \%$ ) and emphysematous pyelonephritis ( 3 out of 359 cases, $0.84 \%$ ).

Among the five cases of graft nephrectomy, 4 showed infarction subsequent to renal vein thrombi and 1 showed infarction following renal artery thrombosis due to aspergillus infection, while one showed acute pyelonephritis with abscesses [Table 6]. 
Table-6: Histopathological diagnosis of the 359 Nephrectomies.

\begin{tabular}{|c|c|c|}
\hline Final Pathological Diagnosis & $\mathbf{N}=359$ & Percentage \\
\hline $\begin{array}{l}\text { Acute pyelonephritis } \\
\text { - With pyonephrosis/ renal abscess }\end{array}$ & 7 & 1.95 \\
\hline $\begin{array}{l}\text { Acute on chronic pyelonephritis with } \\
\text { - Acalculus obstructive uropathy with abscess } \\
\text { - Calculus obstructive uropathy }\end{array}$ & $\begin{array}{c}13 \\
8 \\
5\end{array}$ & $\begin{array}{l}\mathbf{3 . 6 2} \\
2.23 \\
1.39\end{array}$ \\
\hline $\begin{array}{l}\text { Chronic pyelonephritis with } \\
\text { - Acalculus obstructive uropathy } \\
\text { - Calculus obstructive uropathy } \\
\text { - Granulomatous pyelonephritis } \\
\text { > Necrotizing } \\
\text { - Non-necrotising } \\
\text { - Perinephric abscess } \\
\text { - Xanthogranulomatous pyelonephritis } \\
\text { - Complete renal replacement lipomatosis } \\
\text { - Partial renal replacement lipomatosis } \\
\text { - Ossification of kidney } \\
\text { - With simple cysts }\end{array}$ & $\begin{array}{c}272 \\
82 \\
136 \\
27 \\
23 \\
4 \\
4 \\
4 \\
2 \\
2 \\
2 \\
3\end{array}$ & $\begin{array}{l}\mathbf{7 5 . 7 6} \\
22.84 \\
37.88 \\
7.52 \\
6.41 \\
1.11 \\
1.11 \\
3.90 \\
0.56 \\
0.56 \\
0.56 \\
0.84\end{array}$ \\
\hline Progression to end-stage disease / advanced renal disease & 37 & 10.30 \\
\hline Emphysematous pyelonephritis & 3 & $\mathbf{0 . 8 4}$ \\
\hline Autosomal dominant polycystic kidney disease & 5 & 1.39 \\
\hline Renal artery stenosis & 2 & $\mathbf{0 . 5 6}$ \\
\hline Traumatic kidney disease & 9 & 2.51 \\
\hline Congenital malformations (Duplex kidney with chronic pyelonephritis) & 2 & 0.56 \\
\hline $\begin{array}{l}\text { Graft nephrectomies } \\
\text { - In farction subsequent to renal vein thrombosis } \\
\text { - Acute pyelonephritis with abscess }\end{array}$ & $\begin{array}{l}5 \\
4 \\
1\end{array}$ & $\begin{array}{l}1.39 \\
1.11 \\
0.28\end{array}$ \\
\hline Nephrocalcinosis & 1 & $\mathbf{0 . 2 8}$ \\
\hline $\begin{array}{l}\text { Horseshoe kidney with } \\
\text { - Cystic disease and calculus pyelonephritis } \\
\text { - Tuberculous pyelonephritis } \\
\text { - Acalculus pyelonephritis }\end{array}$ & $\begin{array}{l}3 \\
1 \\
1 \\
1\end{array}$ & 0.84 \\
\hline
\end{tabular}

We encountered a wide range of lesions with varied histomorphological features and have attempted to classify these lesions into various categories. However, it is not possible to stringently categorize all lesions as some degree of overlap is seen in the various lesions, and patients may present with multiple lesions and their complications.
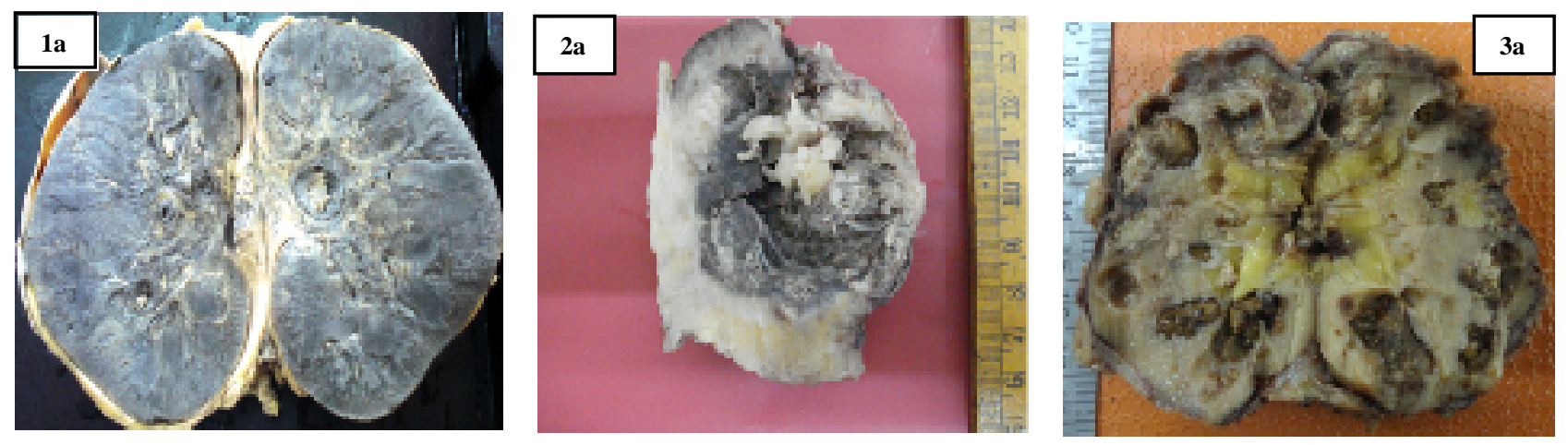

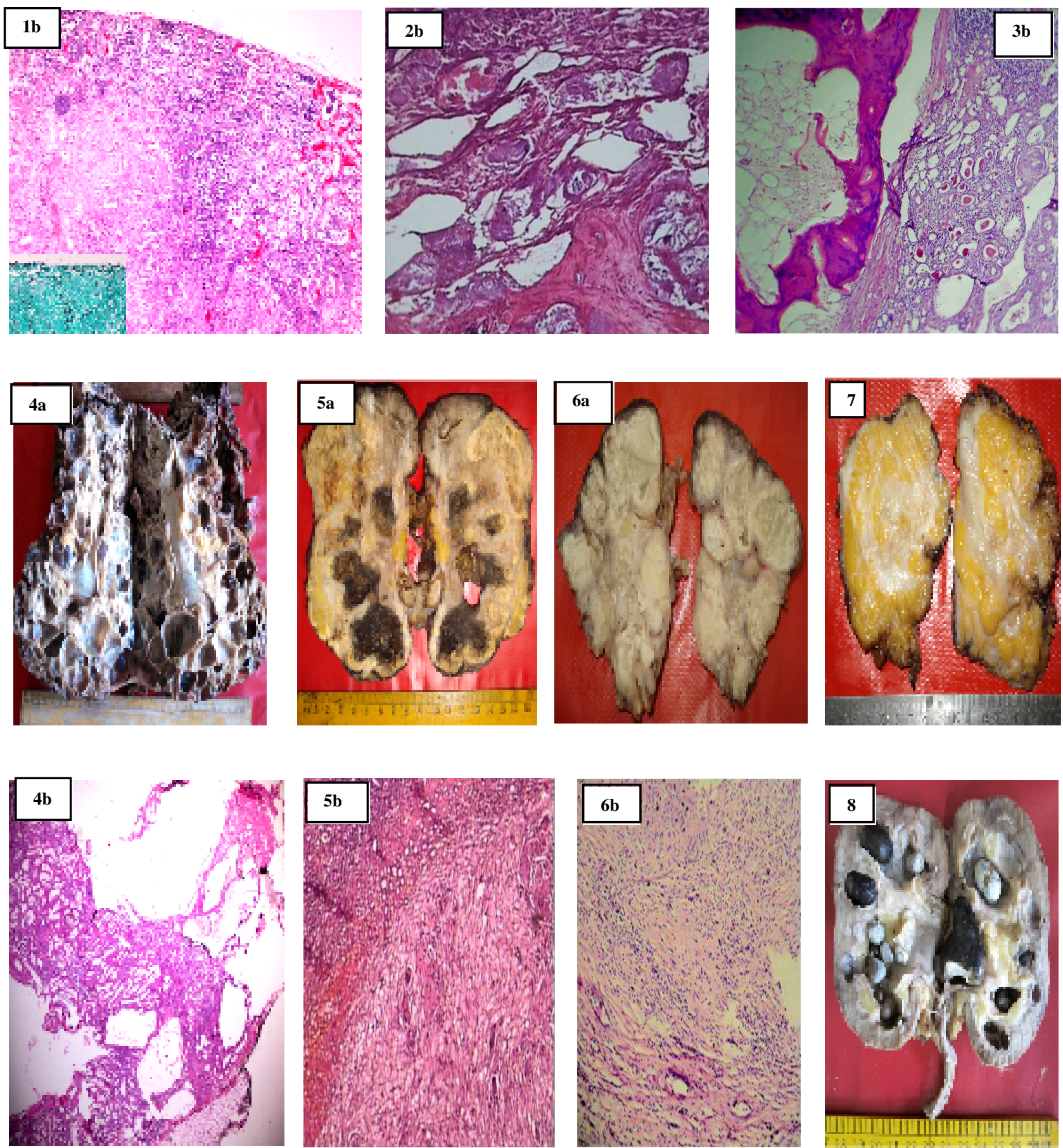

\section{LEGENDS}

1a: Graft Nephrectomy showing a dusky bluish-black kidney following renal vein thrombosis

1b: Microscopy of Graft Nephrectomy showing pale areas of in farction, fung al colonies and neutrophils. Inset shows aspergillus

2a: Nephrectomy showing blackish, necrotic kidney in Emphysematous Pyelonephritis

2b: Microscopy of Emphysematous Pyelonephiritis showing completely necrotic renal parenchyma with air spaces and inflammatory cells.

3a: Nephrectomy showing areas of calcification in Nephrocalcinosis 
3b: Microscopy of Nephrocalcinosis showing large areas of ossi fication in the renal parenchyma

4a: ADPKD showing cysts of varying sizes filled with clear to hemorrhagic fluid

4b: Microscopy of ADPKD showing cysts with denuded epithelium with intervening renal paren chyma

5a: Nephrectomy specimen showing multiple golden- yellow areas of Xanthogranulomatous Pyelonephritis

5b: Nodules of foamy macrophages, cholesterol cleft and giant cells seen amidst the renal parenchyma in Xanthogranulomatous Pyelonephritis

6a: Renal tuberculosis with replacement of the renal parenchyma with locules of cas eous necrotic material

6b: Microscopy of Renal Tuberculosis with epithelioid cell granulomas and caseous necrosis

7: $\quad$ Renal Replacement Lipomatosis with complete replacement of the renal paren chyma with adipose tissue.

8: $\quad$ Renal Calculus Disease and Hydronephrosis

\section{Discussion}

The first planned nephrectomy was performed by Gustav Simon in 1869 for the treatment of ureterovaginal fistula. Thereafter, the procedure of nephrectomy underwent many changes from Kocher in 1878, performing a transperitoneal nephrectomy through midline incision to Clayman in 1990, performing the first laparos copic nephrectomy in 1990 $[3,4]$.

Recent advances in early diagnosis and management have dram atically reduced the number of nephrectomies performed for benign renal diseases in developed countries $[3,5,6]$. Modern interventional radiological support for trauma patients has helped reduce the need to perform nephrectomies in trauma patients $[3,7]$. However, nephrectomies done for benign renal disease has been on the rise in developing countries because of better and more available imaging facilities and better access to healthcare [2,3].

In our study, 359 ANNN cases over 6 year period were analysed at our tertiary care centre. We have compared our study with 2 Indian studies and 1 international study available in literature on histopathology of nonneoplastic nephrectomies. Most of the other studies on nephrectomies included simultaneous study of both neoplastic and non-neoplastic pathology.

Most of the cases in the present study were in the age group 51- 60 years (75 out of 359 cases, 20.89\%) followed by the age group 21-30 years (72 out of 359 cases, $20.06 \%$ ). In the study conducted by Divyashree et al, [2] the highest incidence was in the 3rd decade while in the study by Sujatha et al [8] the highest incidence was also in the 3 rd decade. Mohammad Rafique Zaki.et.al, in a study at Pakistan has reported non-neoplastic renal disease in nephrectomy and observed the highest incidence in the 3rd decade and 4th decade [3].

There was a slight male preponderance with $51.2 \%$ male patients and $48.75 \%$ female patients and the male to female ratio were $1.05: 1$. These finding are in concordance with the finding of Divyashree.et.al ${ }^{[2]}$, who showed a slight male preponderance, where $54.76 \%$ were male and $45.23 \%$ were female. A study of 192 cases by Sujatha et.al [8], also showed similar male preponderance, where $53.12 \%$ were male and $46.87 \%$ were female. Mohammad Rafique Zaki.et.al. showed a 2:1 male : female ratio [3].

In the present study, flank pain was the most common presenting symptom seen in $79.94 \%$ of cases. This observation was similar to a study by Mohammad Rafique Zaki.et.al [3] and Divyashree.et.al [10], who also reported flank pain as the most common clinical feature which was seen in $77.7 \%$ and $70 \%$ of cases respectively.

In the present study, we also observed that nephrectomies were most frequently performed for obstructive uropathy $(47.08 \%)$ followed by nonfunctioning kidney (42.06\%). Obstructive uropathy usually resulted from renal calculi. A similar observation was also noted by Mohammad Rafique Zaki.et.al [3] who found obstructive uropathy caused by calculi in $52.40 \%$. Mohammad Rafique Zaki.et.al [3]. hypothesised that this high incidence is directly related to the delayed presentation of the patients when 
most of the times the kidney is not only full of stones but also has associated pyonephrosis and are often nonfunctioning [3]. In the study conducted by Sujatha et.al, infection rel ated neph ropathy resulting in non or poorly functioning kidney was the most common indication followed by obstructive lesions of the kidney [8].

We also observed that the most common gross pathology was acalculus hydronephrosis (40.67\%) followed by calculus disease with associated hydronephrosis $(33.05 \%)$. There is generally a scarcity of findings of gross pathology of non-neoplastic nephrectomies in literature.

In our study, we observed that the most common final histopathological diagnosis was chronic pyelonephritis seen in $79.38 \%$ cas es. These finding correlated with those observed by Divyashree et.al [2] and Shreedhar et.al [9] who observed chronic pyelonephritis in $84 \%$ and $71 \%$ cases respectively. The most common underlying cause of chronic pyelon ephritis was calculus obstructive uropathy (39.27\%). The next common cause for chronic pyelonephritis was acalculus obstructive uropathy $(25.07 \%)$. All obstructive uropathy, which includes calculus and acalculus uropathy amounted to $64.34 \%$. This finding did not correlate well with the surgical indication of obstructive uropathy (seen in $47.08 \%$ of cas es) in our study for which nephrectomies were done.

PUJ obstruction is defined as an obstruction to the flow of urine from the renal pelvis to the ureter. It can result from anatomic or physiologic defects in the upper ureter, inflammation, obstruction from scar tissue following previous surgery or instrumentation, retroperitoneal fibrosis or even an abnormal vessel over the ureter.

The next most common category which we have labelled as 'Progression to end stage kidney/advanced renal disease' seen in $10.31 \%$ cases showed prominent features of chronicity but short of end stage kidney. These cases showed about $60-70 \%$ s cleros ed glomeruli, extensive tubulointerstitial nephritis and interstitial fibrosis. The patients had compromised renal function and clinically presented as non-functioning kidney.

Xanthogranulomatous pyelonephritis which is a subtype of chronic pyelonephritis was observed in $3.90 \%$ cases (14 out of the 359 cases) in the present study. The clinical diagnoses to these nephrectomies ranged from pyonephrosis, emphysematous pyelonephritis to obstructive uropathy due to renal cal culi. Most patients were female ( 8 out of 14 cases). These finding correlate with those by $\mathrm{Li}$ et.al, [10] who also noted a female preponderance. They noted that xanthogranulomatous pyelonephritis is commonly misdiagnosed preoperatively because it mimics other pathologic conditions such as perinephric abscess and renal cell carcinoma [10].

We had 4 cases of renal replacement lipomatosis, 2 were cas es of partial renal replacement lipomatosis and 2 cases were total renal replacement lipomatosis. The ages of the patients ranged from 35-55 years. All four cases presented as non-functioning kidney, 3 were associated with renal calculus disease. On microscopy, partial to complete replacement of renal parenchyma with adipose tissue secondary to destruction and atrophy of renal parenchyma due to inflammatory changes was seen. Increase in peripelvic and hilar fat in partial renal replacement lipomatosis and hilar fat in total renal replacement lipomatosis was also noted.

We encountered 2 cases of nephrectomies done for renal art ery stenosis. Both of our patients of renal art ery stenosis were young and suffered from severe uncontrolled hypertension. One was a case of autotransplantation for bilateral renal artery disease and developed transplant renal artery stenosis following hypertension. Histology showed severe chronic pyelonephritis with progression to end stage kidney. The second case of renal artery stenosis also presented as a non-functional kidney and histopathology also showed chronic pyelonephritis with progression to end stage and stenosis of renal artery.

We also en countered 3 cas es of complicat ed hors eshoe kidney presenting with non-functional kidney. Out of the 3 cases, one case showed tuberculosis, one had associated polycystic kidney and the third showed features of chronic pyelonephritis. The patient who had horseshoe kidney with associated tuberculosis had urine AFB positive and was on antituberculous treatment for 5-6 months preceding nephrectomy. Tuberculosis presenting in horseshoe kidney is very rare and a single case has been reported in literature [11]. Polycystic horseshoe is also rare entity with only a handful of cases reported in literature $[12,13]$.

We had 5 cases of ADPKD in this study. All cases were above 38 years of age, showed bilateral involvement 
with large voluminous, bosselated kidneys entirely composed of cysts with clear to hemorrhagic fluid. These patients presented with abdominal pain, hypertension and end-stage renal disease. The cysts were lined by cuboidal or flattened epithelium with papillary projections. One of our cases had Berrys aneurysm and one case had associated liver cysts. When ADPKD is suspected, patients should be evaluated for a family history of disease, with specific questioning spanning three generations. Although no consensus criteria have been established, with a negative family history of disease, a presumptive diagnosis can be made when there are bilateral renal cysts, and when two of the following criteria are met: bilateral renal enl argem ent, more than two hepatic cysts, presence of a cerebral aneurysm, or if there is a solitary cyst in the arachnoid, pineal gland, pancreas, or spleen [14]. We also had 3 cases of simple cysts with chronic pyeonephritis in endstage kidneys.

We had one case of nephrocalcinosis in a 31 year old male who presented with chronic kidney disease, stage $\mathrm{V}$ on maintenance hemodialysis. He had secondary hyperparathyroidism, serum parathyroid hormone levels of $359 \mathrm{pg} / \mathrm{ml}$, serum calcium $8.2 \mathrm{mg} \%$, creatinine $4.9 \mathrm{mg} / \mathrm{dl}$, blood urea nitrogen $43 \mathrm{mg} / \mathrm{dl}$. We received bilateral nephrectomy specimens. Grossly, both the kidneys were small contracted in size and showed firm to hard chalky white areas on cut section. Microscopically, kidney showed large deposits of amorphous as well as crystalline material in the tubules, glomeruli and interstitium.

The crystals were of variable shapes and sizes, showed a brown tinge and florid multinucleated giant cell reaction to the crystalline $m$ aterial was noted. Foci of extensive ossification were also seen. Viable renal parenchyma between the amorphous and crystalline deposits showed marked chronic tubulointerstitial inflammation.

We received 7 neph rectomies with clinical diagnosis of emphysematous pyelonephritis, however only 3 of them showed definitive emphysematous pyelonephritis on histopathological examination. All the 3 patients had diabetes and we received either necrotic bits of renal parenchyma or a necrotic blackish kidney Histopathological diagnosis revealed extensive necrotic bits of renal parenchyma with gas filled air spaces, along with dense neutrophilic infiltrate cand showed the presen ce of bacterial colonies.
We had 5 cases of graft nephrectomies, 4 were live related donor transplant and one was a cadaveric transplant. On histopathological examination, 3 showed renal vein thrombosis with infarction of renal transplant. One of the cases was a cadaveric transplant and showed multiple renal infarcts following renal artery thrombosis along with masses of fungal hyphae with morphology res embling aspergillosis with parallel edges, septations and acute angle branching. The other 3 cases of renal vein thrombosis showed usual thrombi.

We also received 2 cas es of duplex kidney, presenting with infection and non-functioning kidney. Histopathology confirmed chronic pyelonephritis with hydronephrosis. We received 9 traumatic nephrectomies, 7 were cases of road traffic accidents, one case presenting 6 months after the trauma. In addition, one was a case of gunshot injury and one a case of stab injury. Histopathologic examination revealed fracture or rupture of the kidney, extensive areas of hemorrhage and foci of necrosis in the renal parenchyma. One of these patients presented 6 months after the injury and showed features of chronic pyelonephritis along with hydronephrosis and abscess. We also had 23 cases of necrotising granulomatous pyelonephritis with classic caseous necrosis indicative of tuberculosis. 4 cases of non-necrotising granulomatous pyelon ephritis were also encountered. 2 cases showed crystalline material in the vicinity of the granulomas and this could probably represent a granulomatous reaction to crystalline and calculus sludge. No caseous necrosis was seen in these cases despite extensive histopathological examination and there was no clinical or radiological evidence of tuberculosis. PCR tests could not be done because of economic reasons.

\section{Conclusion}

This analysis of 359 cases of ANNN at a tertiary care centre gives us a bird's eye view of an entire range of non-neoplastic lesions encountered in nephrectomies received for histopathology. In our study, we found that most patients were in the sixth decade $(20.89 \%)$ and a slight male preponderance was noted. Flank pain was the most common presenting symptom seen in $79.94 \%$ of cases. In our study, we also observed that the most frequent surgical indication for non-neoplastic nephrectomy was obstructive uropathy $(47.08 \%)$ which includes calculus disease and PUJ obstruction followed by non-functioning kidney (42.06\%). On histo- 
pathological examination, the most common gross pathology was acalculus hydronephrosis (40.67\%) and the most frequent histopathological diagnosis was chronic pyelon ephritis seen in $79.38 \%$ cas es. Calculus obstructive uropathy amounted to $39.27 \%$ cases and acalculus obstructive uropathy amounted to $25.07 \%$ cases of chronic pyelonephritis. In addition to this, we also encountered certain rare entities in our study such as renal replacement lipomatosis, horseshoe kidney associated with polycystic disease and tuberculosis, renal artery stenosis, nephrocalcinosis and duplex kidney.

\section{Funding: Nil, Conflict of interest: None. Permission of IRB: Yes}

\section{References}

1. Aiman A, Singh K, Yasir M. Histopathological spectrum of lesions in nephrectomy specimens: A five year experience in a tertiary care hospital. J Sci Soc. 2013; 40(3):148-54. DOI: 10.4103/0974-5009.120058.

2. Divyashree B N, Kusuma V, Madhusudhan H R, Hanumantha R B. Pathological Spectrum of NonNeoplastic Diseases in the Nephrectomy Specimens. J Evidence Based Med and Hlthcare 2014;15(1);19091920. DOI: $10.18410 / \mathrm{jebmh} / 2014 / 279$

3. Zaki M R, Ghazanfar A, Asif K. Nephrectomy for non-traumatic benign renal diseas es: Its indications and outcomes in a developing country. Pak J Med Health Sci. 2012; 6(1):216-9.

4. Zisman A. Laparoscopic nephrou reterectomy: is it always as good as open nephrou reterectomy? Eur Urol. 2010 Nov; 58(5):652-3; discussion 653-4. doi: 10. 1016/j. eururo.2010.08.039. Epub 2010 Sep 15.

5. Al-Khalil N, Panchev P, Kumanov Kh. History of nephrectomy. Khirurgiia(Sofiia). 1999;55(5):38-9.

6. Wszolek MF, Kenney PA, Libertino JA. Nonclamping partial nephrectomy: towards improved nephron sparing. Nat Rev Urol. 2011 Aug 2;8(9):523-7. doi: 10.1038/nrurol.2011.103.
7. Schissel BL, Johnson BK. Renal stones: evolving epidemiology and management. Pediatr Emerg Care. 2011; 27 (7): 676-81. DOI: 10.1097/PEC. 0b013e $3182228 f 10$.

8. Sujatha S, Kowsalya R, Mythri K M. Benign nephrectomies and its variables along with vascular changes in the renal artery: A study from tertiary care centre from south India. J of Nephrol and Urol Res. 2014; 2: 14-18. DOI: http://dx.doi.org/10.12970/2310984X.2014.02.01.3

9. Sreedhar VV, Paul MC, Sirisha O, Shivaram P, Sudhir NV, Chandrakumar S. Pathological study of elective nephrectomies for a two y ear period. Int J Res Med Sc.i 2015;3:1496-500. DOI: 10.18203/23206012.ijrms2015017.

10. Li L, Parwani AV. Xanthogranulomatous pyelonephritis. Arch Pathol Lab Med. 2011 May;135 (5): 671-4. doi: 10.1043/2009-0769-RSR.1.

11. Elangovan S, Bhuvaneswari V, Kannan R R, Dorairajan L N. Interesting case of tuberculosis in a horseshoe kidney mimicking malignant tumor. Indian J Radiol Imaging 2002;12 (4):513-4. http://www.ijri. org/ text. asp? 2002/12/4/513/28527.

12. Chikkannaiah $\mathrm{P}$, Kangle R, Bali A, Honawad MN. Polycystic horseshoe kidney. Med J Armed Forces India. 2015 Jul;71(Suppl 1):S181-3. doi: 10.1016/j. mjafi. 2013.12.002. Epub 2014 Mar 12.

13. Batista Peres LA, Leonel Ferreira JR, Alvares Del fino VD. Polycystic horseshoekidn ey. Nephrol Dial Transplant. 2007 Feb;22(2):652-3 DOI:10.1093 /ndt/ gfl615

14. Halvorson CR, Bremmer MS, Jacobs SC. Polycystic kidney disease: inheritance, pathophysiology, prognosis, and treatment. Int J Nephrol Renovasc Dis. 2010; 3: 69-83. Epub 2010 Jun 24.

\section{How to cite this article?}

Fernandes G and Phadnis P. An analysis of adult non-neoplastic nephrectomies at a tertiary care centre in Mumbai. Int J Med Res Rev 2017;5(02):194-203 doi:10.17511/ijmrr. 2017.i02.15. 